\title{
O liberalismo nos Pareceres de Educação de Rui Barbosa
}

ALBERTO VENANCIO FILHO

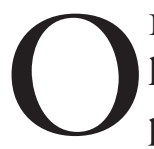
ESTUDO do liberalismo nos Pareceres de Rui Barbosa impõe como preliminar a sua posição em face da doutrina e da influência exercida nos pareceres. O liberalismo brasileiro do século XIX se filia ao liberalismo europeu, mas com a peculiaridade de ambientes e condições inteiramente diferentes do mundo europeu. Na Europa, os homens da época eram praticamente livres, as normas os reconheciam como iguais e pode-se afirmar que os privilégios praticamente se extinguiram.

No Brasil, as circunstâncias eram diversas: existe o culto oficial, privilégios de toda ordem, um sistema de governo pretensamente democrático e, sobretudo, a existência de escravidão. Enquanto o liberalismo europeu se vê diante do socialismo, o liberalismo brasileiro se defronta com instituições arcaicas. Assim se apresenta a peculiaridade do liberalismo brasileiro, pretendendo elevar o país ao nível do Ocidente.

A crença do liberalismo é a crença fundamental na liberdade humana. Nas palavras de Tavares Bastos, grande liberal:

O que caracteriza o homem é o livre arbítrio, o sentimento de responsabilidade que lhe corresponde. A história do progresso humano não é mais com efeito que a das fases do desenvolvimento ou compressão desse divino atributo da criatura a que se dá geralmente o nome de liberdade.

Como comentou Roque Spencer Maciel de Barros (1959):

Figura típica de ilustração brasileira, Rui Barbosa participa intensamente das idéias e dos problemas de seu tempo e do seu país. Os seus olhos estão abertos para tudo o que se passa no ocidente e é clara a sua consciência de que é preciso "ocidentalizar" o Brasil, isto é, de que é necessário acelerar as forças de nosso desenvolvimento histórico. Por vários motivos a indecisão de Rui diante dos caminhos intelectuais que lhe apontava o seu tempo. Ele é e não é um liberal clássico, é e não é um cientificista. Há verdadeiras camadas superpostas no seu pensamento, sem um fio único condutor que as harmonize racionalmente.

Declarava Rui: "Não me acolhi entre as filosofias que fazem da ciência a grande negação. Percorri as filosofias, mas nenhuma ma saciou; não encontrei repouso em nenhuma delas. Pus a ciência acima de todas as coisas, mas não afirmei jamais que a ciência não possa abranger as coisas divinas".

Na expressão de Miguel Reale (1960): “o que nos fica da leitura de suas obras [de Rui] é a impressão de ter ele vivido as abstrações doutrinárias do li- 
beralismo, integrando-as em uma unidade indissolúvel de pensamento e ação". Rui Barbosa não conservou durante a vida um pensamento único, que lhe servisse de orientação no decorrer dos anos. Sensível às idéias do tempo, absorvendo aquelas que melhor se ajustassem ao seu temperamento.

Ao se filiar, porém, ao liberalismo, não adotou uma posição dogmática e sectária, e se abeberou em outras fontes do pensamento. Como todos de sua geração, sofreu o influxo do positivismo. Certa feita, expressou que "o princípio de progressão social que Comte enunciou é a determinante de todos os deveres pelo único de aferição de que a ciência dispõe: o da relação visível das coisas, o da observação real dos fatos". No Parecer sobre o Ensino Primário “o positivismo longe de ser uma seita estéril ou um catecismo de fórmulas abstratas, poderia bem alimentar aspiração aos foros de uma vasta filosofia da realidade, útil aos homens de governo como aos homens de ciência" (Barbosa, 1947a).

Estudando o que chamou de "liberalismo do tipo jurisdicista", evitando a expressão "bacharelista”, Nelson Saldanha (1979) comenta que foi uma idéia constante no Brasil no século XIX, como idéia e como crença, como posição crítica, como esteira doutrinária. Refere-se a Rui Barbosa em seus méritos e deméritos: "Rui Barbosa representou saturadamente as forças e fraquezas daquele liberalismo, seus vazios e seus conteúdos, sua possível e criticável alienação, sua freqüente e louvável eficácia histórica”. Na expressão de Nelson Saldanha, Rui "encarnou também o legalismo coerente tremendamente bem informado, que desempenhou em horas difíceis na defesa dos direitos humanos e do poder civil, um papel realmente inegligenciável” (ibidem).

Várias vezes Rui afirmou no Parlamento do Império: “A Câmara permitirme-á que eu principie pela história, a velha mestra de toda a história humana e começando pela história, seja a da Inglaterra, a veneranda escola do regime, que preponderantemente nos resolva a questão". Em discurso no Senado, respondendo a Pinheiro Machado, diria: "Eu não sou da raça dos sofistas gregos, sou da raça dos constitucionalistas americanos e dois juristas ingleses", ambas expressões do liberalismo.

Certa ocasião, em sessão do Senado de 16 de junho de 1914, o senador Alencar Guimarães, em discussão sobre o estado de sítio, solicitou a Rui Barbosa que não interferisse com as demasias do liberalismo.

E Rui retrucou: “As demasias de meu liberalismo são os ideais que sustento desde que a república se estabeleceu”, e se poderia acrescentar muito antes.

Defendendo a eleição direta a que atribui "uma verdadeira revolução entre nós", vincula-se à liberdade de consciência que deveria ser o instrumento de consolidação democrática. Considerava que o liberalismo é inseparável da democracia, e, pois, um país só será verdadeiramente democrático se a representação exprimir a vontade real do povo.

Dentro de princípios liberais, em carta a um primo, afirmaria em abril de 1881: 
Depois da reforma eleitoral, a que atribuo a importância de uma verdadeira revolução entre nós, é a reforma do ensino público que será, espero, obra do primeiro parlamento renovado; a volta ao ouro é o mais imperioso e o mais próximo problema dentre os que envolvem os destinos de nossa pátria. (Barbosa, 1934)

Outro princípio liberal que defendia era contra o escravagismo. E asseverava que "toda a abolição do cativeiro é uma dupla emancipação, de onde os maiores benefícios auferirá ainda o senhor do que o liberto".

O interesse de Rui Barbosa pela educação vem de longe, pois decorre da veneração pela figura do pai, por quem tinha uma acendrada admiração. "Convosco aprendi a amar e a compreender a santa causa do ensino", e se referia "ao didata e o fazia de modo a mostrar que recebera dele esta mensagem".

As atividades na educação situam-se de 1881 a 1894. Em 1881, a tradução do livro de orientação didática Lições de coisas; em 1882, "O desenho e arte industrial", discurso proferido no Liceu de Artes e Ofício, os discursos e pareceres na qualidade de relator da Comissão de Instrução Pública da Câmara dos Deputados. No ano de 1864, foi presidente da Liga de Ensino no Brasil, e redator principal da Revista, redigindo habitualmente o editorial. Depois só voltou a tratar do assunto de educação em artigo sobre ensino secundário no Diário de Notícias em 1889 e artigos que publicava em 1893 no Jornal do Brasil e, na $A$ Imprensa, apenas dois.

O primeiro artigo de Rui Barbosa, de 10 de junho de 1868, de que se tem conhecimento, é a respeito da criação da Universidade do Rio de Janeiro, quando, aos dezenove anos, estudava Direito em São Paulo. Cogitava-se da transferência para a Corte das duas faculdades da província, e ele combate a medida de excessiva centralização e deseja no Rio de Janeiro uma universidade "mais organizada segundo as idéias liberais como fonte de grande benefícios para o país".

Para compreender a situação do ensino na época e o aspecto renovador do parecer, a exposição de Fernando de Azevedo expõe com precisão tal situação:

Essa educação de tipo aristocrático, destinada antes à preparação de uma elite do que à educação do povo, desenvolveu-se no Império, seguindo, sem desvio sensível, as linhas de sua evolução, fortemente marcadas pelas tradições intelectuais do país, pelo regime de economia patriarcal e pelo ideal correspondente de homem e de cidadão. $\mathrm{O}$ tipo de cultura a que se propunha servir, não se explica apenas pela tradição colonial, de fundo europeu, que de certo modo o preparou, mas se liga estreitamente às formas e aos quadros da estrutura social que persistiram por todo o Império.

O desinteresse pela educação no Império está documentado nas "Falas do Trono", que eram lacunosas em matéria de instrução pública. A primeira, de 1823, apenas se refere à promoção dos institutos públicos quando possível, a necessidade de uma legislação particular; indica várias iniciativas como a compra para uma biblioteca pública de uma coleção de livros da melhor escolha, o 


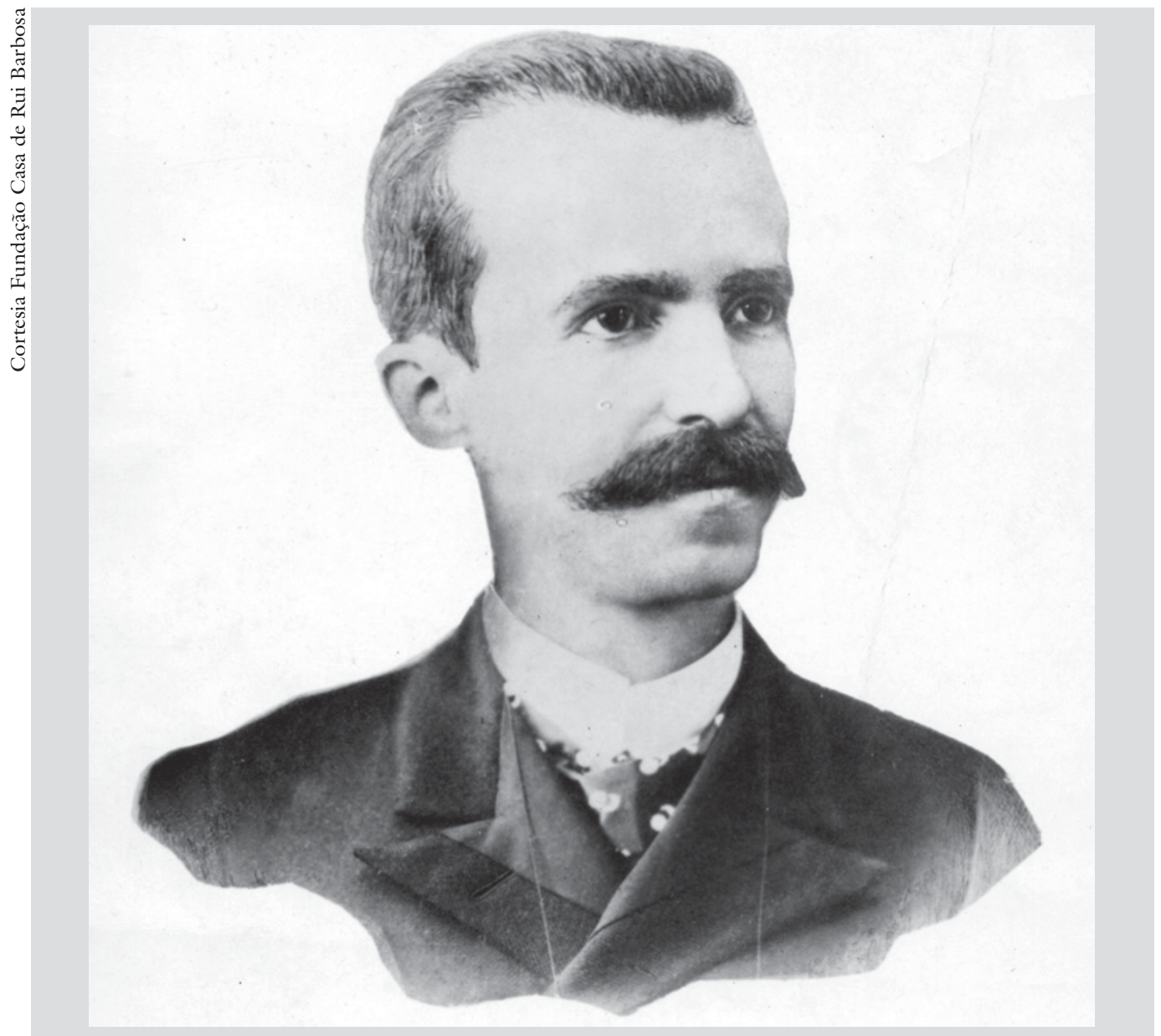

Rui Barbosa (1849-1923) em 1890.

aumento do número de escolas e do ordenado dos mestres, e a abertura de uma escola sobre o ensino mútuo, que era a panacéia da época. A de 1889 era mais explícita, prevendo a criação de escolas técnicas adaptadas às condições locais e duas universidades, uma no Sul e outra no Norte, assim como a da Faculdade de Ciência e Letras, que, apropriadas às províncias, se vinculariam ao sistema universitário, assentando tudo firmemente na instrução primária e secundária.

No período de 1880 até a queda do Império, entretanto, as referências são sumárias, como na de 1880, que se refere aos recursos para a instrução pública, e a de 1884 , que comenta que serão decretados projetos relativos à instrução pública.

Ao redigir os Pareceres, Rui tinha apenas 33 anos, estava no início da sua formação intelectual, já imbuído das idéias liberais, e depois iria trilhar outros caminhos, mas o liberalismo ficará em seu espírito. Nos vários caixotes de livros com que desembarca em Santos vindo do Recife para cursar a Academia de Direito, impressionará os colegas, e neles se incluem pelas grandes obras do liberalismo, entre outros, J. Simon, Politique radicale; Laboulaye, Introduction 
à la histoire du XIX siècle; Discours de Montalembert; Lamartine, Histoire des girondins; Jules Michelet, Histoire de la Revolution Française; Thiers, Etudes Parlamentaires, obras de leitura da juventude.

Formado pela Faculdade de Direito de São Paulo, ali encontra o primado das idéias liberais, tendo como ídolo José Bonifácio, o Moço. Iria exercer por breve período a advocacia na Bahia. É eleito para a Assembléia Provincial e, em 1879, ascende à Assembléia Geral.

Os Pareceres originaram-se da reforma empreendida no Gabinete Sinimbu pelo ministro do Império Carlos Leôncio de Carvalho, professor de Direito da Faculdade de São Paulo, que fez baixar o Decreto n.7.247, de 19 de abril de 1879, reformando o Ensino Primário e o Secundário no município da Corte, e Superior em todo o Império. Continha o Decreto dispositivos de atribuição do Poder Legislativo e dispunha no preâmbulo que esses não seriam executados antes da aprovação daquele poder. Submetido à Câmara, foi encaminhado à Comissão de Instrução Pública.

O acaso levou Rui a se ocupar da questão, reunindo uma notável bibliografia e um levantamento de vários países. Fora Franklin Dória designado relator do decreto, mas nomeado presidente da Província de Pernambuco, é substituído por Rui.

Os Pareceres eram dois: "Reforma do Ensino Primário" e "Várias Instituições Complementares da Instrução Pública e Reforma do Ensino Secundário e Superior".

$\mathrm{O}$ artigo $1^{\circ}$ do Decreto n.7.247 declara que "é completamente livre o ensino primário e secundário no Município da Corte e o superior em todo o Império, salvo a inspeção necessária para garantir as condições de moralidade e higiene". E para aplicação desse dispositivo, a norma de que

não serão marcadas faltas aos alunos e nem serão eles chamados às lições e sabatinas (Art. 20, \$16). E os exames tanto dos alunos como dos que não o forem serão prestados por matérias e constarão de uma prova oral e outra escrita, as quais durarão o tempo que for marcado nos estatutos de cada escola ou faculdade.

A inspeção mencionada no artigo $1^{\circ}$ é objeto de vários dispositivos, prevendo multas e sanções àqueles que deixarem de prestar as informações que as autoridades competentes solicitarem.

O projeto previa a criação no município da Corte de seis inspetores de distrito, assim como o Conselho Diretor de Instrução Pública e Secundária do Município da Corte, composto de várias autoridades. Para inspeção dos estabelecimentos da instituição primária e secundária, criados nas províncias do governo geral, haveria um delegado do governo que assistiria os exames prestados nesses estabelecimentos.

Quanto ao ensino livre, os exames seriam prestados por matéria e contariam de uma prova oral e uma prova escrita, e o estudante não-habilitado poderia prestar novo exame na época própria ou seguinte. 
Às instituições que funcionassem regularmente por sete anos consecutivos e provassem que pelo menos vinte alunos tivessem obtido o grau acadêmico, o governo concederia o título de Faculdade Livre com privilégios das escolas oficiais.

Nas expressões de Lourenço Filho:

os pareceres representam algo de valioso. De mais sugestivo e significativo, porque na verdade, fixam alguma coisa de universal e eterno. Em Rui é a profunda fé no valor do espírito humano, na capacidade de engenho de cada homem de criar, experimentar e corrigir, no exercício da liberdade, a que essa criação e experimentação a cada época renovadas, podem e devem conduzir.

Segundo Francisco Venancio Filho (1944):

Dois traços, entretanto, dos mais acentuados, se revelam nos dois Pareceres. De um lado a grande preocupação, que os domina pelo espírito científico, pelo valor espiritual e pragmático da ciência, pelo que ela representa, na formação da personalidade, como conteúdo e como método. O outro traço expressão do liberalismo é a constante impregnação do sentimento de liberdade, que farmeia toda a obra de pensamento e de ação de Rui Barbosa.

Rui afirma nos Pareceres: "Revela instaurarmos o grande serviço de instrução nacional contra a ignorância, cuja frente incumbe ao parlamento a missão de colocar-se, impondo intransigentemente a tibieza de nosso governo o cumprimento do seu supremo dever para com a pátria". E em seguida: "Ninguém contestará a necessidade de organizar, rigorosamente, nas condições mais perfeitas de excelência e eficácia, o ensino oficial".

E acentuava:

A chave misteriosa das desgraças que nos aflige é esta e só esta. A ignorância popular mar da servilidade, da miséria. Eis a grande ameaça contra a existência constitucional e livre da nação. Eis o formidável inimigo, o inimigo que se abriga nas entranhas do país. Para o vencer releva instaurarmos o serviço da defesa nacional contra a ignorância [...] Cumpre renovar o método, orgânico, substancial, absolutamente nas nossas escolas. Ou antes cumpre criar o método, porque o que existe entre nós usurpou um nome, que só por antífrase lhe assentaria, não é o método de ensinar, é pelo contrário o método de inabilitação para aprender.

Em matéria de ensino, atendendo a um postulado liberal e democrático, enfatizava a presença do ensino público:

Não há de desconhecer a evidência da incapacidade atual do indivíduo e da associação entre as sociedades mais adiantadas, para substituir, na educação do povo a ação ampla, sistematizada múltipla do Estado; não contestará a necessidade de organizar rigorosamente nas condições mais perfeitas de excelência e eficácia, de atividade e ciência, o ensino oficial.

E para cumprimento desse propósito, propunha pioneiramente a criação de um Ministério da Instrução Pública: "Em vez de promover medidas tendentes a enfraquecer a organização central do ensino, a vossa comissão encara, por 
conseguinte, como providência de largo alcance e urgência imperiosa a criação do ministério da instrução pública" (ibidem).

A escola leiga, conseqüência da separação da Igreja e do Estado, é também defendida nos pareceres. Rechaçando o ensino religioso professado obrigatoriamente a todos os alunos, o catecismo ensinado pelo professor facultativamente, a religião excluída do programa escolar, mas lecionada na escola pelos que o desejarem, advoga a instrução religiosa excluída do programa escolar e do edifício escolar. Discorda do decreto que encarrega ao funcionário do Estado o ensino do catecismo, que seria aberrar do rumo. Assim prosseguia: "aproveitem pois as nossas contribuições à instrução comum, ficando a cada religião o prover como puder, e ao seu modo, a educação religiosa das crenças nascidas no seu grêmio" (ibidem). E

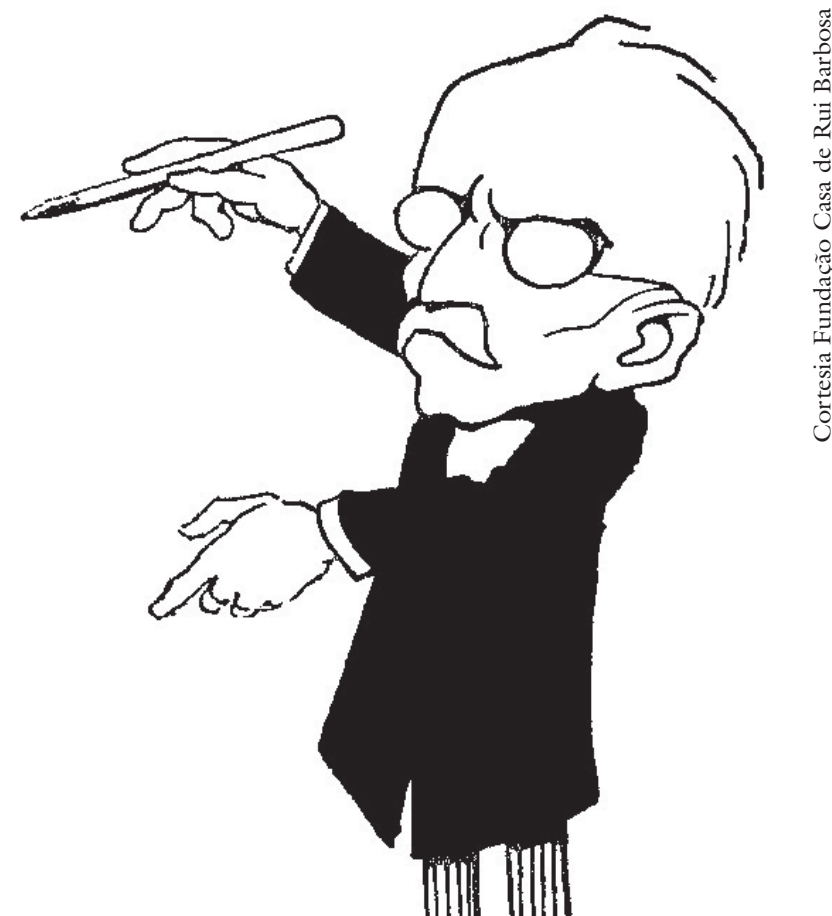

Caricatura de Rui Barbosa, 1917. mais adiante: "Instituída assim, a escola comum não importará dogmas, religiosos ou irreligiosos, materialistas ou espiritualistas, deístas e ateus, racionalistas ou confessionais" (ibidem).

As relações entre o Estado e a liberdade de ensino estão bem definidas no projeto, obedecendo a uma orientação liberal. O relatório abraça a liberdade de ensino em toda a sua plenitude, considerando que o "Estado é apenas a organização legal das garantias de paz comum e mútuo respeito entre as várias crenças, convicções e tendências" (ibidem), e rejeita o detestável erro que promove o Estado "ao papel de Mentor do espírito humano e dos pais de família". Mas acrescenta "que o Estado é o grande representante da inteligência contra o obscurantismo, é o inimigo armado das trevas, é o irradiador vitorioso da luz" (ibidem).

Em outro passo, ele contrapõe dois tipos de instituição:

Há instituições e instituições. Umas, firmadas na pretensão da supernaturalidade da sua origem, fazem da própria instabilidade o dogma individual, ponto de partida e a verdade suprema do direito natural. A essas certamente não pode ser simpático o desenvolvimento da consciência popular e do sentimento individual.

A que aproxima dos princípios liberais "tem intuito declarado precisamente em proteger a expansão calma e progressiva da liberdade humana e da von- 
tade popular, fazem pelo contrário consistir a legitimidade de sua existência e estabilidade de sua situação, indefinida das suas formas, e na ilimitada estabilidade de suas leis" (ibidem). Mas acrescentava: "Para essas instituições a educação popular não é perigo, nem ameaça, nem incômodo é, ao contrário, uma condição de vida normal, de segurança, de desenvolvimento tranqüilo" (ibidem).

O princípio liberal se afirmava nos Pareceres na defesa da mulher, em que não desconhecia nenhuma das qualidades precisas para "devassar todos os domínios do conhecimento" e confirmava esse pensamento ao dizer que "no projeto de reforma do ensino superior já lhe abrimos sem reservas as portas de nossas faculdades" (ibidem).

As concepções liberais se refletem também no capítulo ao tratar das faculdades de Direito. Propõe a exclusão da cadeira de Direito Eclesiástico "sem utilidade real, sem verdadeiro caráter de necessidade pesaria indevidamente no curso jurídico, em detrimento do estudo que importava adicionar-lhe ou desenvolver" (ibidem).

Em outro passo, também não aceita a cadeira de Direito Natural, e propõe a inclusão da cadeira de Sociologia, e afirma: "O pensamento da Comissão em todo o seu trabalho está em substituir a ideologia, isto é, o culto da abstração da frase da hipótese pelos resultados do método científico" (ibidem).

E mais adiante: "ao direito natural, pois que é metafísica antepomos a sociologia, ainda não rigorosamente científica é certo na maior parte dos seus resultados, mas científica nos seus processos, nos seus intuitos, na sua influência sobre o desenvolvimento da inteligência humana" (ibidem).

Os Pareceres não tiveram aplicação prática, não foram discutidos no Parlamento, e nas expressões de Rui foram condenados às "traçarias dos arquivos". Mas Rui recebe o título de conselheiro, e por três horas, a convite do imperador Pedro II, debate com ele os Pareceres.

Nessa posição liberal, Rui Barbosa é bem o representante da classe média. Conforme San Tiago Dantas (2001):

Tudo na sua figura, no seu pensamento e no seu destino dele fazem o herói dessa burguesia nascente, que encheu o vazio interno da sociedade de senhores e escravos. Seus planos de ensino, sua preocupação com a criação de um espírito técnico e artesanal no brasileiro já revelam, sob o antigo regime, para onde aponta seu espírito renovador.

Comentou Vicente Licínio Cardoso que

procedimento de Rui pareceu-lhe inexplicável, pois é de fato monumental, foi esquecido por Rui, o jornalista, o político colaborador robusto da Constituinte, o senador das três décadas republicanas à Presidência da República. Foi ele mesmo que nunca mais falou naquele programa magistral, molde oracular em que poderia ter vazado o idealismo orgânico da República.

Estava equivocado Vicente Licínio Cardoso quando afirmou que Rui abandonou as questões de ensino. Na plataforma da campanha civilista de 1910, 


\section{Rui voltaria ao tema:}

Mas nesse assunto [instrução pública] não há porque me demorar. As minhas idéias amplamente desenvolvidas nos dois pareceres parlamentares de 1882 não desmereceram em atualidade. Eles mostram a intensidade da minha devoção à causa do ensino popular e encarando todas as questões suscitáveis a respeito da instrução pública nos seus diferentes graus, deixam ver sobre cada uma o espírito dos mais esclarecidos. Não tenho, pois, que desperdiçar tempo e frases em generalidades ociosas.

E precisando as modificações do regime em vigor que julgava necessárias, enumerou o melhoramento do Ensino Secundário nos estabelecimentos federais; a remodelação do ensino jurídico a desenvolvimento dos gabinetes de ensino prático nas escolas de Medicina. Merece ênfase a proposta de criação de uma universidade no Rio de Janeiro, que deveria obedecer aos padrões da universidade alemã, que examina em vários aspectos.

O liberalismo de Rui, que surge em 1880 com o discurso sobre a eleição direta e que se encerra com a Oração aos moços, de 1921, tem nos Pareceres marcas profundas.

Referências bibliográficas

BARBOSA, R. Mocidade e exílio (Cartas). Rio de Janeiro: Companhia Editora Nacional, 1934.

Reforma do Ensino Primário e várias instituições complementares de Instrução Pública. In : _. O. Obras completas de Rui Barbosa. Rio de Janeiro: Ministério de Educação e Saúde, 1947a. v.X, t.I, II, III, IV.

Reforma do Ensino Secundário e Superior. In : __. Obras completas de Rui

Barbosa. Rio de Janeiro: Ministério de Educação e Saúde, 1947b. v.XI.

Escritos e discursos seletos. Rio de Janeiro: Aguilar, 1960.

BARROS, R. S. M. de. A idéia de Universidade e a ilustração brasileira. São Paulo: s. n., 1959.

COSTA, J. C. Contribuição às Histórias das Idéias no Brasil. Rio de Janeiro: José Olympio, 1956.

DANTAS, F. S. T. Rui Barbosa e a renovação da sociedade. In: . Palavras de um professor. 2.ed. Rio de Janeiro: Forense, 2001.

LACOMBE, A. J. À sombra de Rui Barbosa. Rio de Janeiro: Fundação Casa de Rui Barbosa, 1984.

Prefácio aos Pareceres de Ensino Primário. v.X, t.I.

LOURENÇO FILHO, M. B. Prefácio à "Lições de Coisas de Lições de Coisas" de Rui Barbosa. In: BARBOSA, R. Obras completas de Rui Barbosa. Rio de Janeiro: Ministério de Educação e Saúde, 1947. v.II (1885), t.I.

A pedagogia de Rui Barbosa. 3.ed. São Paulo: Melhoramentos, 1966. 
MARTINS, W. História da inteligência brasileira. São Paulo: Cultrix, 1978. v.IX (18771896).

MOREIRA, T. M. Prefácio ao Parecer de Instrução Secundária e Superior. v.XI, t.I.

PENTEADO, J. de A. A consciência didática no pensamento pedagógico de Rui Barbosa. São Paulo: Nacional, 1984. (Col. Brasiliana, 378).

REALE, M. Posição de Rui Barbosa no mundo da filosofia. In: BARBOSA, R. Escritos e discursos seletos. Rio de Janeiro: Aguilar, 1960.

SALDANHA, N. História das idéias políticas no Brasil. Recife: Universidade Federal de Pernambuco, 1968.

Rui Barbosa e o bacharelismo liberal. In: A história das idéias políticas no Brasil. São Paulo: Convívio, 1979.

VENANCIO FILHO, F. Os Pareceres de Rui Barbosa. In: Cultura política - 1944.

VIANA FILHO, L. A vida de Rui Barbosa. 7.ed. São Paulo: Martins, 1965.

Alberto Venancio Filho é advogado, jurista, professor e historiador, membro da Academia Brasileira de Letras (ABL). @ - avf@bpbc.com.br

Recebido em 8.10.2007 e aceito em 12.10.2007. 